\title{
Transformation of zooplankton communities during pollution and restoration of lakes
}

\author{
Olga Derevenskaya \\ Kazan Federal University \\ Kazan, Russia \\ oderevenskaya@mail.ru
}

\begin{abstract}
Studies were carried out on three lakes in Kazan (Russia). The lakes were severely polluted due to sewage discharge of industrial enterprises. In the period of 1984-1995 measures were taken for two lakes to restore their water quality. According to the project, the majority of industrial waste water was assigned to the treatment plant; at the bottom, contaminated sediment was cleaned, sewers were built, temporary flowage was organized, and beach was equipped. Water quality in lakes has improved considerably. We investigated changes in zooplankton communities during the recovery measures immediately after their completion and 20 years later. We have found that the response of zooplankton to pollution reduction is represented by the increase in the number of zooplankton species, a number of dominant species, abundance and biomass. A share of Cladocera increased in the Nizhniy Kaban Lake, while Copepoda and Cladocera shares increased in lake Sredniy Kaban. Enhanced development of these groups of zooplankton caused corresponding changes in taxonomic indicators based on the ratio of the values of abundance and biomass of zooplankton major groups, saprobic index. Follow-up study of the lakes showed that with existing high anthropogenic load, repeated remediation is required in 15-20 years.
\end{abstract}

Keywords- zooplankton; restoration; lake; communities; eutrophication; pollution

\section{INTRODUCTION}

Water objects of urbanized areas, as a rule, have a strong anthropogenic impact, leading to their contamination and eutrophication. There is a need to carry out activities aimed at their restoration. However, examples of successful restoration of water bodies remain few due to the complexity and insufficient knowledge of the process. The changes in zooplankton communities during these processes are studied even less.

One of the most revealing examples of a comprehensive solution to problems can be the situation with the River Rhine. The ecological state of this river has been improved as a result of the implementation of a set of legislative, administrative, economic and technological measures [1]. A significant number of projects and programs for the restoration of water bodies and sustainable water management have been successfully implemented in the Danube River Basin [2]. In
Turkey, two lakes have been restored thanks to reduced wastewater leaks and biomanipulation [3]

The methods used for the restoration of water bodies can be divided into two groups: preventive measures carried out in the catchment area and tributaries in order to restrict the supply of nutrients and pollutants to water bodies and recovery, directly affecting various components of aquatic ecosystems in order to change the desired concentration of ingredients, the number of aquatic organisms, hydrological characteristics, etc. [4].

The first group includes measures to divert or purify industrial and storm sewage, contaminated surface runoff, and a number of other agrotechnical, forestry and hydrotechnical measures that prevent the entry of biogenic elements and pollutants into the basin $[2,3,5]$.

The most commonly used remediation measures from the second group are aeration of water [6], removal or shielding of bottom sediments [7, 8], creation or strengthening of flow, chemical and mechanical methods for controlling blue-green algae, precipitation of phosphorus in water [9], the creation of bioplatoes from mollusks [1, 10] and higher aquatic plants [11], biomanipulation [10]. The use of these methods allows one, with varying degrees of success, to restore water objects, but in order to achieve a sustainable state, a set of preventive and recovery measures should be used.

In this connection, long-term observations of the state of the zooplankton communities of the Kaban lakes in Kazan (Russia) are of great interest.

The Kaban lake system in Kazan includes three lakes (Nizhniy, Sredniy and Verkhniy). These are small lakes, they have mixed food (groundwater, atmospheric precipitation, surface runoff) (table 1). In the Nizhniy and Sredniy Kaban lakes, industrial and domestic wastewater was discharged, so by the 1970-s they were heavily polluted. In order to improve the quality of water in lakes, a health improvement project was developed and implemented by municipal services in 19811995. According to the project, the majority of industrial waste water was assigned to the treatment plant, the bottom with contaminated sediment was cleaned, sewers were built, temporary flowage was organized and beach have been 
developed. However, nowadays, rain sewage in lakes dumped from the watershed.

Lakes are located in the central part of the city, they are used for recreational and sporting purposes, and they are an element of the green framework of the city. The purpose of our research was to identify changes in the zooplankton

TABLE I. MORPHOMETRIC CHARACTERISTICS OF LAKES.

\begin{tabular}{|l|l|l|l|}
\hline \multicolumn{1}{|c|}{ Index } & N.Kaban & S.Kaban & V.Kaban \\
\hline The surface area of the lake, ha & 47,5 & 129,7 & 24,7 \\
\hline Length, $\mathrm{km}$ & 1,8 & 3,1 & 1,0 \\
\hline Width: max / average, $\mathrm{m}$ & $346 / 260$ & $622 / 128$ & $369 / 245$ \\
\hline Depth: maximum / average, $\mathrm{m}$ & $16,3 / 8,3$ & $22,8 / 7,8$ & $15,4 / 7,9$ \\
\hline Volume of the lake, thousand $\mathrm{m} 3$ & 3950,79 & 11156,20 & 1930,30 \\
\hline Length of shoreline, $\mathrm{km}$ & 4,5 & 10,1 & 3,3 \\
\hline
\end{tabular}

communities of lakes in the process of health improvement measures immediately after their completion and also after 2530 years in conditions of continuing anthropogenic impact.

\section{MATERIAL AND METHODS}

Samples were taken at 1-3 deepwater stations on each of the lakes. In 1995-1997 and in 2001, samples were collected every 10-14 days during the growing season (April-October), in 1989 - monthly, in 1991-1994, 2002, 2009-2010 - once a main season of the growing season, in 2013-2014 - monthly during the summer period. Samples were collected by the Jedi network in horizons, selected according to the stratification of water by temperature. A total of 732 quantitative samples of zooplankton were collected and processed during the study period. Sampling was carried out in accordance with conventional hydrobiological methods [12]. To identify changes in the zooplankton community, indicators based on an assessment of the taxonomic structure of the zooplankton community were used: the ratio of the main zooplankton groups by abundance and biomass [13]; ratio of Crustacea biomass to Rotatoria biomass $\left(\mathrm{B}_{\mathrm{Cr}} / \mathrm{B}_{\mathrm{Rot}}\right)$; ratio of Cladocera abundance to Copepoda abundance $\left(\mathrm{N}_{\mathrm{Cl}} / \mathrm{N}_{\mathrm{Cop}}\right)$; ratio of Cyclopoida biomass to Calanoida biomass $\left(\mathrm{B}_{\mathrm{Cycl}} / \mathrm{B}_{\mathrm{Cal}}\right)$; the value of the average individual mass of the zooplankton for the community as a whole $\hat{\mathrm{w}}=\mathrm{B} / \mathrm{N}$ [14]. In relation to the plankton of eutrophic (E) and oligotrophic (O) species, the trophic index E/O was calculated [15]. The degree of zooplankton community diversity was estimated from the Shannon index (by abundance and biomass) [16]. The index of saprobity was calculated by the method of Pantle and Bucca in the modification of Sladechek [17].

To assess the effectiveness of recovery measures, we conditionally identified several periods that differ in the degree and nature of the anthropogenic load. So, in the 1980-s the load of pollutants was the largest, and the water in the lakes was characterized as "extremely dirty". This period was called the "period of greatest pollution". In 1984-1986, restorative measures were carried out at Lake Nizhniy Kaban, and in 1984-1995 - on the lake Sredniy Kaban. These periods were called "periods of recovery". The subsequent period was described as "post-recovery". In order to assess the response of zooplankton communities to the complex of restoration measures, the indicators of zooplankton communities were compared in the selected periods, compared with the literature data. Also, a survey was conducted with the Verkhniy Kaban lake, which was not affected.

\section{RESULTS AND DISCUSSION}

In the Nizhniy Kaban lake, the intensification of industrial pollution caused a significant decrease in the number of zooplankton species from 116 [18] to 36 [19], dominated mainly by rotifers of the genus Brachionus. The complex of species that was developed during this period can be considered to be resistant to severe pollution conditions. The reduction in the number of species and the dominance of species belonging to the Brachyonidae family is characteristic of severe pollution conditions and is described in many literary sources $[20,21$, etc.]. During the period of restoration, the crustaceans Cyclops strenuus Fischer, Acanthocyclops vernalis (Fischer) are included in the dominant complex in addition to rotifers (Asplanchna priodonta Gosse, Keretella quadrata (Muller), Brachionus angularis Gosse). As a result of the health measures, the number of species increased to 80 . The most common rotifers were A. priodonta, K.quadrata, and Filinia longiseta (Ehrenberg) and crustaceans Daphnia cucullata Sars, Eudiaptomus gracilis (Sars). Biomass was often dominated by copepods E. gracilis and rarely - D. cucullata.

In the Sredniy Kaban lake, the increase in pollution caused a reduction of species composition (from 67 species in 19501964 [18] to 34 in 1981-1983 [19]) with a reduction in the number of dominant species. Chemical contamination occurred against the background of thermal pollution, which greatly increases the toxicity of substances for hydrobionts. As a result of the health measures, the number of species increased to 82, among them Rotifera - 32 species (39\%), Cladocera - 31 (38\%), Copepoda - 19 (23\%); the number of dominant species increased to four. After the completion of the health improvement measures (1996 - 2014 yy.), 67 species were encountered, among them Rotifera - 27 (40\%), Cladocera - 26 (39\%), Copepoda - 14 (21\%). K.quadrata, B. angularis, B.longirostris, D. cucullata, E.gracilis were the dominant in abundance. E.gracilis, D.cucullata and $B$. longirostris were the dominant in biomass. The dominant complex usually formed 1-2 species.

In 1951, 46 species were found in the zooplankton of Lake Verkhniy Kaban [18]. In 1981-1984, in the composition of zooplankton there were 43 species [19], in 1991-2014 - 68 species; among them Rotifera - 31 species (46\%), Cladocera $22(32 \%)$, Copepoda - $15(22 \%)$. The most diverse group of rotifers was represented; they also form the dominant complex consisting of 2-5 species.

In the zooplankton of Lake Nizhniy Kaban, the leading role in abundance and biomass was played by Copepoda $(60 \%$ and $75 \%, 55 \%$ and $80 \%$ respectively of the total abundance and biomass) in 1981-1983 and 1984-1986. After the restoration measures, the share of rotifers increased (by abundance), but Copepoda dominated the biomass. There is a decrease in the average individual body weight of organisms and a decrease in the Cladocera abundance ratio to the 
Copepoda population. The values of the Shannon index increased from $1.90 \pm 0.49$ to $2.24 \pm 0.05$ (by abundance) and from $1.58 \pm 0.39$ to $1.69 \pm 0.07$ (by biomass). The values of the trophy index corresponded in 1981-1983 to the hypereutrophic waters (5.5), decreased as a result of the health measures to eutrophic (4.6); however, in subsequent years the values of this index rose to hypertrophic (5.3). After the completion of activities, the share of rotifers in the community increased with a decrease in the proportion of crustaceans; accordingly, the indicator $\mathrm{B}_{\mathrm{Cr}} / \mathrm{B}_{\text {Rot }}$ increased and $\mathrm{N}_{\mathrm{Clad}} / \mathrm{N}_{\mathrm{Cop}}$ decreased. The values of the indicators of the taxonomic structure of the community corresponded to the water bodies of the eutrophic type. The species diversity of zooplankton increased.

In Lake Sredniy Kaban, Rotatoria played a leading role both in abundance and in biomass during the period of strong industrial pollution (1981-1984). In the structure of the zooplankton community, the share of rotifers decreased, but the proportion of Cladocera and Copepoda increased; the average individual weight of the zooplankter increased, $\mathrm{B}_{\mathrm{Cr}} / \mathrm{B}_{\text {Rot }}, \mathrm{N}_{\mathrm{Clad}} / \mathrm{N}_{\mathrm{Cop}}$; the share of the Calanoida decreased in 1989-1995. The values of Shannon's index increased to the values typical for mesotrophic lakes; the values of the trophic index $(\mathrm{E} / \mathrm{O})$ decreased from the values typical for hypereutrophic lakes (5.5) to eutrophic (2.2). After the completion of remedial measures, but with a fairly high anthropogenic load in the form of storm water inflows, contaminated surface runoff, the following trends were observed in the community. There was an increase in the share of rotifers in the community and a decrease in the proportion of Cladocera (in number), which is often observed in the eutrophication of lakes; the indicator $\mathrm{B}_{\mathrm{Cr}} / \mathrm{B}_{\mathrm{Rot}}$, and $\mathrm{B}_{\mathrm{Cyc}} / \mathrm{B}_{\mathrm{Cal}}$ decreased but $\mathrm{N}_{\mathrm{Clad}} / \mathrm{N}_{\mathrm{Cop}}$ increased. The species diversity has decreased (according to the Shannon index). In general, the structural indicators of zooplankton, in comparison with the previous period, are characteristic of hypertrophic reservoirs. During the period of greatest contamination, the values of the trophic index $(\mathrm{E} / \mathrm{O})$ increased to the values typical for hyper-eutrophic lakes (5.5), and during the period of health-improving measures the eutrophic eutrophic level decreased on the border with the mesotrophic (2.2); however, in the subsequent period they increased to hypertrophic (7).

The ratio of the main zooplankton groups in the Verkhniy Kaban Lake according to the average data for 1981-1984 and 1991-2014 has changed slightly. Rotifers predominated in these periods $(50 \%$ and $49 \%$, respectively) and copepods (44\% and $40 \%$, respectively). Biomass was dominated by Copepoda, although their share in biomass formation decreased, and the proportion of Rotifera and Cladocera increased, which is typical of eutrophic lakes. The redistribution of the shares of Cladocera and Copepoda reflected the increase in $\mathrm{N}_{\text {Clad }} / \mathrm{N}_{\mathrm{Cop}}$, and the decrease in Calanoida in the increase in $\mathrm{B}_{\mathrm{Cycl}} / \mathrm{B}_{\mathrm{Cal}}$. The values of trophic index (E/O) increased from 4.0 in 1951 to 4.2 in 1991-2014, also indicating an increase in trophic levels.

The lowest mean values of zooplankton abundance and biomass were recorded in Lake Nizhniy Kaban during the period of the most severe pollution (1981-1983) and amounted to 215.86 thousand ind $/ \mathrm{m}^{3}$ and $2.25 \mathrm{~g} / \mathrm{m}^{3}$, respectively. The increase in quantitative indicators occurred during the period of health improvement measures. The abundance of zooplankton increased to 319.09 thousand ind. $/ \mathrm{m}^{3}$ (1.5 times), biomass - up to $3.54 \mathrm{~g} / \mathrm{m}^{3}$ (1.5 times). At the same time, there was a redistribution of the abundance and biomass values in the seasonal aspect. The highest values are at the end of spring and early summer. After completion of the measures, the total number of zooplankton increased to 428.81 thousand ind $/ \mathrm{m}^{3}$ (1.3 times), and the biomass slightly decreased to $3.2 \mathrm{~g} / \mathrm{m}^{3}$. The highest values of quantitative indicators are characteristic of the epilimnion and the lowest values for the hypolimnion. Differences in the vertical distribution of zooplankton, in addition to trophic relationships with phytoplankton, are associated with abiotic conditions, in particular, with a low oxygen content in the hypolimnion.

In Lake Sredniy Kaban, the smallest zooplankton abundance and biomass were also recorded during the period of greatest pollution (1981-1984), the mean values for the zooplankton abundance and biomass during the growing season were 98.34 thousand ind. $\mathrm{m}^{3}$ and $0.68 \mathrm{~g} / \mathrm{m}^{3}$, respectively. During the period of restoration activities, the abundance of zooplankton increased to 392.09 thousand ind. $/ \mathrm{m}^{3}$ ( 4 times), and biomass to $3.34 \mathrm{~g} / \mathrm{m}^{3}$ (5 times). The value of the biomass corresponded to $\beta$-mesotrophic lakes (according to the classification of S.P. Kitaev (1984)). The distribution of zooplankton abundance and biomass values during the growing season is similar to the Nizhniy Kaban lake. In the vertical distribution of zooplankton, as well as in the Lower Kaban lake, the largest values of abundance and biomass are recorded in the epilimnion, the smallest - in the hypolimnion. After the completion of the rehabilitation activities, the total number and biomass of zooplankton decreased to 239.03 thousand ind.$/ \mathrm{m}^{3}$ (1.6 times) and 2.12 $\mathrm{g} / \mathrm{m}^{3}$ (1.6 times), respectively, which corresponds to $\beta$ mesotrophic waters (according to S.P. Kitaev (1984)).

In Lake Verkhniy Kaban, during the period of the study, a gradual increase in the mean values of zooplankton quantitative indices was observed (Fig. 1, 2). In the case of the Verkhniy Kaban lake, the growth of quantitative indicators during the period of research is a consequence of the intensive process of anthropogenic eutrophication. So, in 1981 the average number and biomass during the growing season were 76.92 thousand ind. $/ \mathrm{m}^{3}$ and $0.71 \mathrm{~g} / \mathrm{m}^{3}$, in $1997-600.93$ thousand ind. $\mathrm{m}^{3}$ and $4.0 \mathrm{~g} / \mathrm{m}^{3}$, respectively. Copepoda were predominant in adundance in 1984 and 1994, but in 19951997 Rotifera prevailed. The share of Cladocera during all the years of research was relatively low. The biomass was dominated by Copepoda. 
Fig. 1. Dynamics of zooplankton abundance (N, thousand ind./m3) in the lake Verkhniy Kaban.

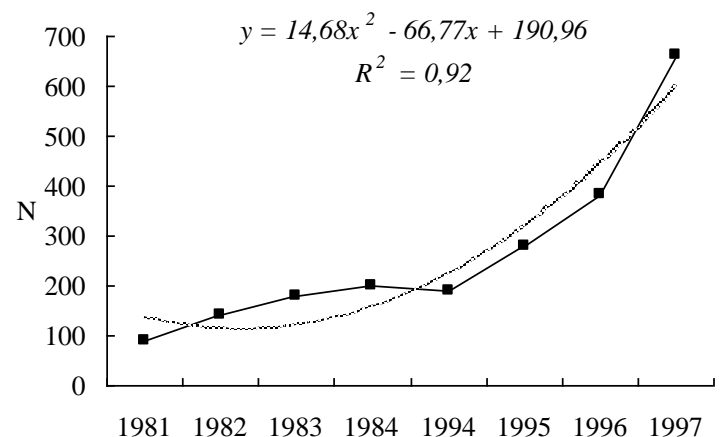

Fig. 2. Dynamics of zooplankton biomass (B, g/m3) in the lake Verkhniy Kaban.

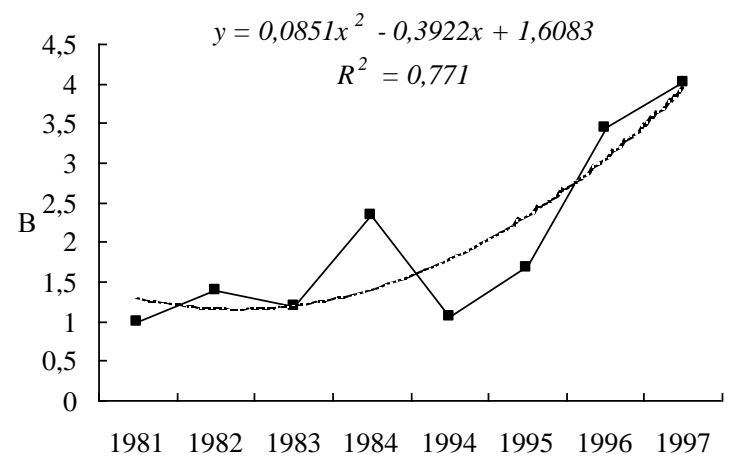

In the seasonal distribution of abundance and biomass of zooplankton in Lake Verkhniy Kaban, the greatest values are at the end of May. The vertical distribution of zooplankton, as well as in the Nizhniy and Sredniy Kaban lakes, was characterized by the highest concentration of zooplankton in the epilimnion with the predominance of Copepod. In the hypolimnion, rotifers predominantly prevailed.

The change in the level of pollution of lakes at different stages of anthropogenic impact caused a change in the proportion of indicator species in communities and the values of the saprobity index. In the period from 1981 to 2014 for all three lakes, saprobic index values ranged in the $\beta$ mesosaprobic zone. On Lake Nizhniy Kaban during the dredging period, there was a tendency for the index values to increase and decrease in the subsequent period. A similar situation was observed at Lake Sredniy Kaban. An increase in the index values may be due to the receipt of organic substances during hydromechanical work [22].

Our studies revealed trends in indicators of Kaban Lakes zooplankton at different stages and in different types of human exposure and health (Table 2).

\section{CONCLUSION}

Thus, studies have shown that the health measures carried out in 1984-1995 significantly improved the ecological state of the Nizhniy and Sredniy Kaban lakes. The concentration of toxic substances has decreased, the quality of water has increased, and the zooplankton communities have been restored. The response of communities to reduce pollution was manifested in an increase in the number of species, an increase in the number of dominant species, including representatives of all zooplankton groups in the dominant complex. Now zooplankton of the lake Nizhniy Kaban consists of 80 species, the lake Sredniy Kaban - 67, the lake Verkhniy Kaban - 68. Reducing the level of pollution caused an increase in its abundance and biomass. At the same time, in the Nizhniy Kaban Lake the share of Cladocera increased, in the Sredniy Kaban Lake - of Copepoda and Cladocera. The intensive development of these zooplankton groups caused corresponding changes in taxonomic indices, based on the ratio of the abundance and biomass of the main zooplankton

TABLE II. RENDS IN ZOOPLANKTON INDICATORS IN DIFFERENT TYPES OF ANTHROPOGENIC IMPACT

\begin{tabular}{|c|c|c|c|c|c|c|c|}
\hline \multirow[t]{2}{*}{ Index } & \multirow{2}{*}{$\begin{array}{l}\text { Eutro- } \\
\text { phica- } \\
\text { tiona }\end{array}$} & \multirow{2}{*}{$\begin{array}{l}\text { Pollu- } \\
\text { tiona }\end{array}$} & \multicolumn{2}{|c|}{ N.Kaban } & \multicolumn{2}{|c|}{ S.Kaban } & \multirow{2}{*}{$\begin{array}{c}\text { V. } \\
\text { Kaban } \\
1994- \\
2014\end{array}$} \\
\hline & & & $\begin{array}{l}1984- \\
1986\end{array}$ & $\begin{array}{l}\text { 1991- } \\
2014\end{array}$ & $\begin{array}{l}1989- \\
1995\end{array}$ & $\begin{array}{l}1997- \\
2014\end{array}$ & \\
\hline $\begin{array}{l}\text { Number } \\
\text { of species }\end{array}$ & $=$ & $\downarrow$ & $=$ & $\uparrow$ & $\uparrow$ & $\downarrow$ & $\bar{\uparrow}$ \\
\hline $\begin{array}{l}\text { Number } \\
\text { of } \\
\text { dominant }\end{array}$ & $\downarrow$ & $\downarrow$ & $=$ & $\uparrow$ & $\uparrow$ & $=$ & $=$ \\
\hline $\begin{array}{l}\text { BCr/BRo } \\
\mathrm{t}\end{array}$ & $\downarrow$ & - & $\uparrow$ & $\uparrow$ & $\uparrow$ & $\downarrow$ & $\uparrow$ \\
\hline $\begin{array}{l}\text { NClad/N } \\
\text { Cop } \\
\end{array}$ & $\uparrow$ & - & $\uparrow$ & $\downarrow$ & $\uparrow$ & $\downarrow$ & $\uparrow$ \\
\hline $\begin{array}{l}\mathrm{BCycl} / \mathrm{B} \\
\mathrm{Cal}\end{array}$ & $\uparrow$ & - & - & 个 & $\uparrow$ & $\downarrow$ & $\uparrow$ \\
\hline $\begin{array}{l}\text { H,bit/ind. } \\
(\mathrm{N})\end{array}$ & $\downarrow$ & $\downarrow$ & $\uparrow$ & 个 & $\uparrow$ & $\downarrow$ & $\uparrow$ \\
\hline $\begin{array}{l}\mathrm{H} \text {, bit/ind } \\
\text { (B) }\end{array}$ & $\downarrow$ & $\downarrow$ & $\uparrow$ & $\uparrow$ & $\uparrow$ & $\uparrow$ & $\uparrow$ \\
\hline$\hat{\mathrm{W}}$ & $\downarrow$ & $\downarrow$ & $\uparrow$ & $\uparrow$ & $\uparrow$ & $\uparrow$ & $\downarrow$ \\
\hline $\begin{array}{l}\mathrm{R}: \mathrm{Cl} \text { :Cop } \\
(\mathrm{N})\end{array}$ & $\begin{array}{l}\mathrm{R} \uparrow \\
\mathrm{Cl} \uparrow \\
\mathrm{Cop} \downarrow \\
\end{array}$ & $\begin{array}{l}\mathrm{R}^{\downarrow} \\
\mathrm{Cl}^{\downarrow} \downarrow \\
\mathrm{Cop}^{\downarrow} \downarrow\end{array}$ & $\begin{array}{l}\mathrm{R}= \\
\mathrm{Cl} \uparrow \\
\mathrm{Cop} \downarrow\end{array}$ & $\begin{array}{l}\mathrm{R} \uparrow \\
\mathrm{Cl}^{\downarrow} \downarrow \\
\mathrm{Cop} \downarrow\end{array}$ & $\begin{array}{l}\mathrm{R}^{\downarrow} \\
\mathrm{Cl} \uparrow \\
\mathrm{Cop} \uparrow\end{array}$ & $\begin{array}{l}\mathrm{R} \uparrow \\
\mathrm{Cl}^{\downarrow} \downarrow \\
\mathrm{Cop} \downarrow\end{array}$ & $\begin{array}{l}\mathrm{R} \uparrow \\
\mathrm{Cl}^{\uparrow} \\
\mathrm{Cop} \downarrow\end{array}$ \\
\hline $\begin{array}{l}\mathrm{R}: \mathrm{Cl}: \mathrm{Cop} \\
\text { (B) }\end{array}$ & $\begin{array}{l}\mathrm{R} \uparrow \\
\mathrm{Cl} \uparrow \\
\mathrm{Cop} \downarrow\end{array}$ & $\begin{array}{l}\mathrm{R}- \\
\mathrm{Cl}^{\downarrow} \downarrow \\
\mathrm{Cop} \downarrow\end{array}$ & $\begin{array}{l}\mathrm{R}^{\downarrow} \\
\mathrm{Cl} \uparrow \\
\mathrm{Cop} \downarrow\end{array}$ & $\begin{array}{l}\mathrm{R}= \\
\mathrm{Cl} \uparrow \\
\mathrm{Cop}^{\downarrow}\end{array}$ & $\begin{array}{l}\mathrm{R}^{\downarrow} \\
\mathrm{Cl}^{\uparrow} \\
\mathrm{Cop} \uparrow\end{array}$ & $\begin{array}{l}\mathrm{R} \uparrow \\
\mathrm{Cl}^{\uparrow} \uparrow \\
\mathrm{Cop} \downarrow\end{array}$ & $\begin{array}{l}\mathrm{R} \uparrow \\
\mathrm{Cl} \uparrow \\
\mathrm{Cop} \downarrow\end{array}$ \\
\hline $\mathrm{E} / \mathrm{O}$ & $\uparrow$ & $\uparrow$ & $\downarrow$ & $\uparrow$ & $\downarrow$ & $\uparrow$ & $\uparrow$ \\
\hline Total N & $\uparrow$ & $\downarrow$ & $\uparrow$ & $\uparrow$ & $\uparrow$ & $\downarrow$ & $\uparrow$ \\
\hline Total B & $\begin{array}{lll} & & \\
\downarrow & \text { or } \\
& \end{array}$ & $\downarrow$ & $\uparrow$ & $\downarrow$ & $\uparrow$ & $\downarrow$ & $\uparrow$ \\
\hline$S$ & $\uparrow$ & $\uparrow$ & $\downarrow$ & $\downarrow$ & $\uparrow$ & $\uparrow$ & $\downarrow$ \\
\hline
\end{tabular}

groups; the average weight of the zooplankter increased. Reduction of the degree of pollution caused a decrease in the share of organisms in the community - indicators of $\beta-\mu-, \beta-\alpha-$ 
mesosaprobic waters and an increase in oligo- and o- $\beta$ mesosaprobic and a decrease in the values of the saprobity index. The increase in the number of dominant species, species richness reflected the increased values of the Shannon index.

Thus, the restoration measures had a significant effect on the structure of zooplankton communities: the number of species, the abundance and biomass of zooplankton increased, the values of indicators characterizing the structure of zooplankton communities changed. A similar complex of restoration measures can be recommended for the restoration of water bodies contaminated with industrial wastewater. However, the subsequent observation of these water bodies has shown that with a sufficiently high anthropogenic load, a single restoration is not enough. A large number of suspended solids, oil products, heavy metals enter the closed water bodies located in urbanized areas, in the form of storm, surface, emergency sewage, which leads to the contamination of water and bottom sediments, and adversely affects the communities of hydrobionts. To maintain the state of the ecosystem after 15-20 years, it is required to carry out the restoration activities again.

\section{Acknowledgment}

We are grateful to the staff and students of the laboratory of optimizing water ecosystems, Kazan Federal University, who participated in the collection and processing of samples of water and zooplankton. We express special gratitude to the head of the laboratory and the department, to the ideologist of the work, Professor N.M. Mingazova.

\section{References}

[1] S. Hilt, E. Gross, M. Hupferi, H. Morscheid, J. Mahlmann, A. Melzer, J. Poltz, S. Sandrock, E. Scharf, S. Schneider, K. Weyerh, «Restoration of submerged vegetation in shallow eutrophic lakes- A guideline and state of the art in Germany», Limnologica, vol. 36, № 3, pp. 155-171, 2006.

[2] D. Hering, A. Borja, J. Carstensen, L. Carvalho, M. Elliott, K. Feld, A Heiskanen, R. Johnson, J. Moe, D. Pont, A. Solheim, W. Bund, «The European Water Framework Directive at the age of 10: A critical review of the achievements with recommendations for the future», Science of the Total Environment, 408, № 19, pp. 4007-4019, 2010.

[3] M. Beklio glu, T. Bucak, J. Coppens, G. Bezirci, Ü. N. Tav sano glu, A Çakıro־glu, E.E. Levi, S. Erdo־gan, N. Filiz, K. Özkan, A. Özen, «Restoration of Eutrophic Lakes with Fluctuating Water Levels: A 20Year Monitoring Study of Two Inter-Connected Lakes», Water, 9 (2), 127; https://doi.org/10.3390/w9020127, 2017.

[4] O. Yu. Derevenskaya, N.M. Mingazova, «Communities of zooplankton in lakes in the course of their contamination and restoration», Hydrobiological journal, vol. 36, № 1, pp. 1-7, 2000.

[5] J. V. Cruz, D. Pacheco, J. Porteiro et al. «Sete Cidades and Furnas lake eutrophication (São Miguel, Azores): Analysis of long-term monitoring data and remediation measures», Science of the Total Environment, vol. 520, pp. 168-186, 1 July 2015.

[6] W. Ma, T. Huang, X. Li, «Study of the application of the water-lifting aerators to improve the water quality of a stratified, eutrophicated reservoir», Ecological Engineering, vol. 83, pp. 281-290, October 2015.

[7] V.P. Gorelov, «Restoration and functioning of bottom biocenoses of reservoirs of the Volga-Akhtuba floodplain under the influence of largescale dredging works (on the example of Degtyarnoye lake)», Electronic scientific and educational journal of the WSPU "Borders of cognition", Vol. 38, №. 4, pp. 125-128, 2015.

[8] M.E. Shabarova, S.V. Maksimova, «Rehabilitation of urban water bodies using Geotube technology», International Student Scientific Bulletin, № 3, pp. 87-91, 2015.

[9] S.E. Jorgensen, Management of lake systems. Moscow: Agropromizdat, $1985,157 \mathrm{p}$

[10] R. Gulati, L. Pires, E. Donk, «Lake restoration studies: Failures, bottlenecks and prospects of new ecotechnological measures», Limnologica, Vol. 38, Issues 3-4 pp. 233-247, 22 October 2008.

[11] A.M. Naumova, M.N. Goncharova, A.Yu. Naumova, «Use of aquatic plants to clean water and soil of a fishery water body from organic and inorganic contamination», Problems of veterinary sanitation, hygiene and ecology, V. 14, № 2, pp. 72-77, 2015.

[12] Guidelines for the collection and processing of materials in hydrobiological studies in freshwater, Zooplankton and its products, ZIN -GOSNIORH, Leningrad, 1982, $33 \mathrm{p}$.

[13] N.M. Kryuchkova, «Structure of the zooplankton community in water bodies of different types», Production-hydrobiological studies of aquatic ecosystems, Leningrad: Zoological institute, 1987, pp. 184-198.

[14] I.N. Andronikova, Structural and functional organization of zooplankton of lake ecosystems of different trophic types, Sankt-Petersburg: Nauka, 1996, $189 \mathrm{p}$

[15] L. Hakkari, «Zooplankton species as indicators of environment», Aqua fennica, Helsinki, pp. 46-54, 1972 .

[16] C.E. Shannon, W. Weaver, The mathematical theory of communication Urbana, $1965,117 \mathrm{p}$.

[17] V. Sladecek, «System of water quality from biological point of view», Egetnisse der Limnologie Heft. 7. Arhiv fứr Hydrobiologie, Becheft, 7, pp. 1-288, 1973

[18] V.V. Nechkina, «Sanitary-biological study of the Lake Sredniy Kaban», Collection of works on zoology, Kazan, Issue 1, 1965, pp. 25-53.

[19] N.M. Mingazova, Y.S. Kotov, The Kazan Lakes. Kazan: Publishing house of Kazan University, 1989, $174 \mathrm{p}$

[20] M.B. Ivanova, «Influence of pollution on plankton crustaceans and the possibility of their use for determining the degree of contamination of rivers», Methods of biological analysis of fresh waters, Leningrad: Zoological institute, 1976, pp. 68-80.

[21] A.V. Makrushin, «Biological analysis of water quality», Leningrad, $1974,60 \mathrm{p}$.

[22] V.E. Sazonov, A.P. Istomin, N.S. Kalyuzhnaya, I.Yu. Kalyuzhnaya, «Methodological and legal aspects of restoration and ecological rehabilitation of water objects (by the example of the Volga-Akhtuba floodplain)», Electronic scientific and educational journal of WSPU "Borders of knowledge", vol.38, No. 4, pp. 9-19, 2015.

[23] O. Derevenskaya, N. Mingazova, L. Pavlova, «Lake water quality of Kazan city (Russia) Kaban lake in the anthropogenic pollution conditions and improving actions implementation», International Journal of Applied Engineering Research, vol. 10, № 24, pp. 44682-44687. 2015. 